\title{
Binder jetting 3D printing process optimization for rapid casting of green parts with high tensile strength
}

\author{
Zhao-fa Zhang ${ }^{1}$, *Li Wang ${ }^{1,2}$, Lin-tao Zhang ${ }^{1}$, Peng-fei Ma', Bing-heng Lu' ${ }^{\mathbf{1}, \mathbf{2}}$, Chen-wei Du ${ }^{\mathbf{3}}$ \\ 1. Micro and Nano Technology Research Center, State Key Laboratory for Manufacturing Systems Engineering, Xi'an Jiaotong University, \\ Xi'an 710049, China \\ 2. National Innovation Institute of Additive Manufacturing, Xi'an 710065, China \\ 3. Beijing Hangxing Machinery Manufacturing Co., Ltd., Beijing 100013, China
}

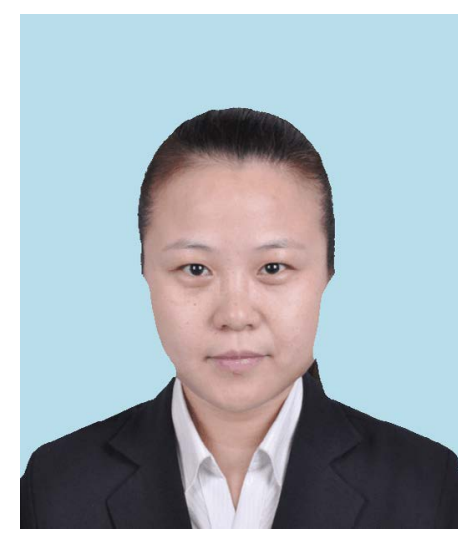

*Li Wang

Female, bom in 1973, Associate Professor. Her research interests mainly focus on additive manufacturing technology, micro-nano manufacturing, flexible electronic devices, and opto-electronic devices manufacturing.

E-mail: wanglime@mail.xjtu.edu.cn

Received: 2021-03-24

Accepted: 2021-07-14

\begin{abstract}
Binder jetting 3D printing is a rapid, cost effective, and efficient moulding/ core making process, which can be applied to a large variety of materials. However, it exhibits a relatively low green-part strength. This may cause the collapse of the printed parts during de-caking and the pick-up procedure, especially in the case of smallscale structures, such as thin walls, tips, and channels. In this work, polyvinyl alcohol (PVA) was used as the additive in coated sand powder. By exploiting the binding effect between the two composites (thermoplastic phenolic resin and PVA) triggered by the binder, bonding necks firmly form among the sand particles, improving the greenpart strength of the coated sand printed parts. Experiments based on the Taguchi method were used to investigate the relationship between the process parameters and the green-part tensile strength. The following set of optimal process parameters was identified: $50 \mathrm{wt} . \%$ alcoholicity of the binder, $75 \%$ binder saturation, $0.36 \mathrm{~mm}$ layer thickness and 4.5wt.\% PVA content. Further, the effect of such parameters on the green-part tensile strength was determined via statistical analysis. The green part of an engine cylinder head sand pattern with complex cavity structures was printed, and the green-part tensile strength reached 2.31 MPa. Moreover, the ZL301 aluminum alloy impeller shape casting was prepared using sand molds printed with the optimal process parameters. The results confirm that the proposed binder jetting 3D printing process can guarantee the integrity of the printed green parts and of small-size structures during decaking and the pick-up procedure. Furthermore, the casting made from the printed sand molds exhibits a relatively high quality.
\end{abstract}

Key words: binder jetting; green-part strength; coated sand; polyvinyl alcohol; rapid casting

CLC numbers: TG242; Document code: A; Article ID: 1672-6421 2021 04-335-09

\section{Introduction}

Traditional sand casting has a history of more than 3,000 years, which can be traced back to the Shang dynasty. In the past, sand mold manufacturing mainly relied on timeconsuming manual work, limiting the accuracy and complexity of the castings. Rapid casting technology is a combination of traditional casting and additive manufacturing (AM), which is considered to be the base of the fourth industrial revolution ${ }^{[1]}$. Ever since its inception, it has brought unprecedented innovation to the foundry sector.

As one of the seven AM technologies defined by the ASTMF-42 committee, binder jetting (BJ), originally known as "three-dimensional printing technique" ${ }^{[2,3]}$ (3DP), is a process based on the inkjet printing technology in which a liquid bonding agent is selectively deposited to bind powder materials ${ }^{[4]}$. In the past few years, BJ has evolved into a rapid, cost-effective, and efficient moulding/core making process, which can 
be applied to a large variety of materials. This technology is currently one of the solutions available on the market to manufacture complex cavity structures and sand molds with a short delivery cycle. Moreover, it can also be used to cast single or small batch customized metal parts ${ }^{[5]}$.

The schematic of the binder jetting $3 \mathrm{D}$ printing process is shown in Fig. 1. A computer controls the inkjet printhead to distribute a precise quantity of binder onto the surface of the powder bed. In this fashion, single-layer powder bonding is achieved. Then, the build platform moves down by a distance defined by the layer thickness before coating surface again with a new layer of powder. This process repeats itself until all layers are completely printed, and the final layer of powder is also successfully spread.

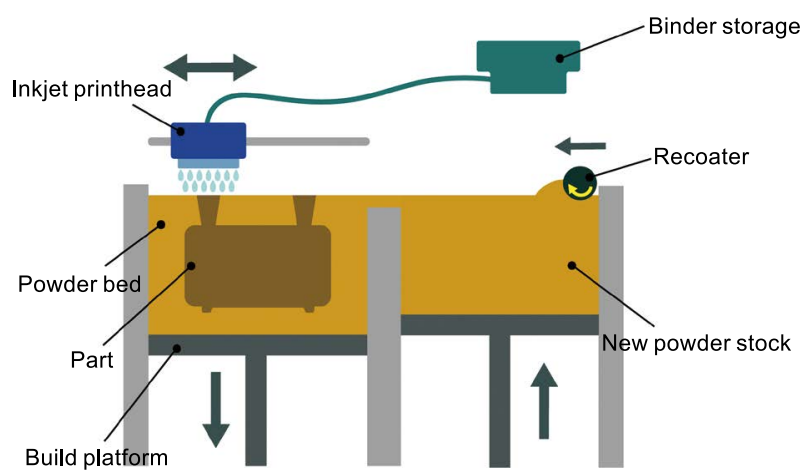

Fig. 1: Schematic illustration of binder jetting 3D printing process

Recently, ExOne ${ }^{\mathrm{TM}}$, Voxeljet ${ }^{\mathrm{TM}}$, and ZCorp ${ }^{\mathrm{TM}}$ have developed industrial systems to produce sand molds via the BJ process ${ }^{[6]}$. Snelling et al. ${ }^{[7]}$ used the ExOne ${ }^{\mathrm{TM}}$ furan resin in combination with a sulphonic acid catalyst to print dog-bone shaped sand samples. The specimens exhibited a tensile strength of 1.3 MPa after curing for a minimum of $24 \mathrm{~h}$. Drokina et al. ${ }^{[8]}$ tested the tensile strength of ZCast molding sand in samples with different thicknesses and introduced the impregnation process to improve the tensile strength before calcination. Their results showed that the maximum green-part tensile strength reachable by applying this process measured $0.667 \mathrm{kPa}$ for a thickness of $25 \mathrm{~mm}$. Snelling et al. ${ }^{[9]}$ compared two commercially available 3DP powders, the ViriCast ${ }^{\mathrm{TM}}$ produced by Viridis3D, and the ZCast ${ }^{\circledR}$ produced by 3D Systems, on a 3D Systems Spectrum Z510 3D printer. The samples were cured at $400^{\circ} \mathrm{F}$ $\left(204.4{ }^{\circ} \mathrm{C}\right)$ for $5 \mathrm{~h}$ and their tensile strengths were $0.16 \mathrm{MPa}$ and $0.06 \mathrm{MPa}$, respectively. Tian et al. ${ }^{[10]}$ improved the raw coated sand by adding $\alpha$-plaster. The tensile strength of their green parts with $3 \% \alpha$-plaster reached $0.931 \mathrm{MPa}$. Zhao et al. ${ }^{[11]}$ investigated the effect and mechanism of a binder system on the properties of micro-jetting and bonding additive-manufactured sand molds by using sodium silicate and alkaline phenolic resin as binder, respectively. The results showed that when the binder saturation level reached $25 \%$ and the layer thickness was $0.32 \mathrm{~mm}$, the tensile strength of the sodium silicate sand mold and the phenolic resin sand measured $0.85 \mathrm{MPa}$ and 1.2 $\mathrm{MPa}$, respectively.
The green-part strength directly affects the integrity of the printed parts during de-caking and the pick-up procedure, when compressed air or a vacuum cleaner is used to remove the loosely attached sand. The green parts fabricated by the binder jetting $3 \mathrm{D}$ printing process exhibit relatively low strength, but only a few studies focusing on its improvement are available. In this work, PVA was used as the powder additive in coated sand powder, and the ethanol was chosen as the main component of the binder. Experiments based on the Taguchi method were used to investigate the relationship between the process parameters and the green-part tensile strength. A set of optimal process parameters were identified, and their effect on the green-part tensile strength was revealed via statistical analysis. Moreover, based on the optimal process parameters, the subsequent experimental verifications were carried out.

\section{Experimental procedure}

\subsection{Starting material and preparation}

The mixed powder containing coated sand and PVA was chosen as the starting material. The coated sand is generally made of silica, thermoplastic phenolic resin, urotropin, calcium stearate, and other additives ${ }^{[12]}$. The thermoplastic phenolic resin was coated onto the surface of the silica sand. Such polymer is soluble in ethanol and in several organic solvents but not in water. The coated sand exhibits high demolding ability, high temperature resistance, and strong adaptability, and it can be used to produce cast steels, as well as iron and aluminum parts. GHD600 coated sand, produced by Hüettenes-Albertus Chemische Werke GmbH (HA), was employed. Its characteristic parameters are shown in Table 1.

PVA is a flake-like, odorless, white powder with excellent adhesion and film-forming properties. Due to the strongly hydrophilic hydroxyl groups in its molecular backbone, PVA is a water-soluble polymer. Moreover, it can quickly decompose when its temperature reaches $220{ }^{\circ} \mathrm{C}^{[13,14]}$ and volatilize from the printed parts due to the subsequent thermal treatment. In this work, the PVA1788-300 powder additive was used and its characteristic parameters are listed in Table 2.

A V-shaped three-dimensional motion mixer was used to mix together the GHD600 coated sand and PVA powder for $2.5 \mathrm{~h}$, then, ball-milled at a speed of $120 \mathrm{r} \cdot \mathrm{min}^{-1}$ for $15 \mathrm{~min}$. In this fashion, the PVA powder with small grain size was fully and evenly mixed into the gap of the coated sand. The morphologies of the PVA1788-300 powder, of the GHD600 coated sand, and of the mixed powder observed by an optical microscope, respectively, are shown in Fig. 2.

\subsection{Sample preparation}

Since the thermoplastic phenolic resin on the coated sand surface is soluble in ethanol and PVA is soluble in water, the ethanol aqueous solution was chosen as one of the components of the low viscosity binder, which prevents the nozzle from clogging. The binder used in this work is non-toxic, environmentally friendly, and it can quickly volatilize from 
Table 1: Characteristic parameters of GHD600 coated sand

\begin{tabular}{ccccc} 
AFS & $\begin{array}{c}\text { Melting point of resin } \\
\text { membrane }\left({ }^{\circ} \mathrm{C}\right)\end{array}$ & Angle coefficient & $\begin{array}{c}\text { Phenolic resin content } \\
(\text { wt. } \%)\end{array}$ & $\begin{array}{c}\text { Gas evolution } \\
\left(\mathrm{mL} \cdot \mathrm{g}^{-1}\right)\end{array}$ \\
\hline $110-140$ & 92 & 1.1 & $2.2-2.4$ & $\leq 24$
\end{tabular}

Table 2: Characteristic parameters of PVA1788-300

$\begin{array}{cccc}\text { Mesh } & \text { Alcoholysis degree (\%) } & \text { Ash (wt.\%) } & \begin{array}{c}\text { Density } \\ \left(\mathrm{g} \cdot \mathrm{cm}^{-3}\right)\end{array} \\ 300 & 86-90 & \leq 0.5 & 0.8\end{array}$
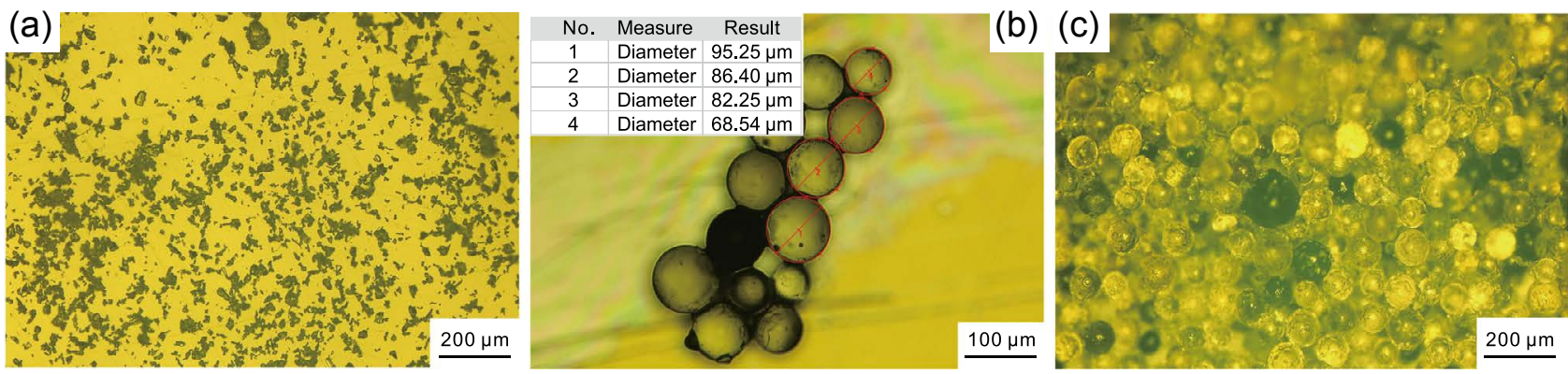

Fig. 2: Morphology of powder materials observed via an optical microscope: (a) PVA1788-300; (b) GHD600 coated sand; (c) mixed powder

the printed parts after the printing process is done. This helps to reduce the gas evolution volume of the printed molds since only a small quantity of binder residues remain in the powder material. In order to achieve good inkjet performance and surface wettability of the binder, a small amount of surfactant was added into the binder system. The binder characteristic parameters were measured by a Brookfield DV2T viscometer and a BZY-1 surface tension meter at $22.5^{\circ} \mathrm{C}$, and the results are listed in Table 3.

The standard tensile samples of coated sand were printed by a self-developed binder jetting sand mold (core) 3D printer [Fig. 3(a)]. The geometry of a standard tensile sample ${ }^{[15]}$ is shown in Fig. 3(b). According to the printing method shown in Fig. 3(c), the printhead deposits the binder in the $X Y$ plane to form a single layer of the standard tensile sample, and the final sample is accumulated layer by layer along the $Z$ axis. Figure 4 shows the process diagram for printing the green samples of coated sand. After printing, the samples were remained in the forming box for $24 \mathrm{~h}$ with $30 \%$ humidity and a temperature of $28{ }^{\circ} \mathrm{C}$. The loosely attached powder was then removed by a vacuum cleaner, and the green samples of coated sand were obtained [Fig. 3(d)]. A Gemini SEM 500 field emission scanning electron microscope was then employed to observe the bonding necks among the sand particles.

Table 3: Binder characteristic parameters

\begin{tabular}{|c|c|c|c|c|}
\hline Temperature $\left({ }^{\circ} \mathrm{C}\right)$ & Surfactant & $\begin{array}{l}\text { Surfactant content } \\
(w t . \%)\end{array}$ & $\begin{array}{l}\text { Surface tension } \\
\qquad\left(\mathrm{mN} \cdot \mathrm{m}^{-1}\right)\end{array}$ & $\begin{array}{l}\text { Viscosity } \\
\text { (mPa-s) }\end{array}$ \\
\hline 22.5 & BYK D200 & 3 & 20.3 & 2.75 \\
\hline
\end{tabular}

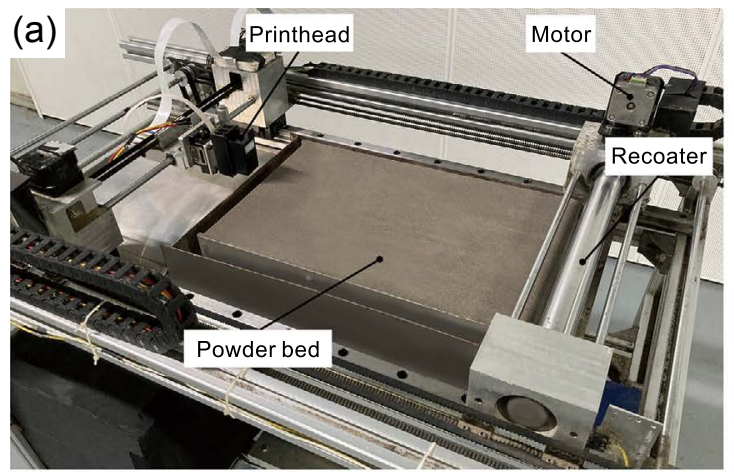

(b)

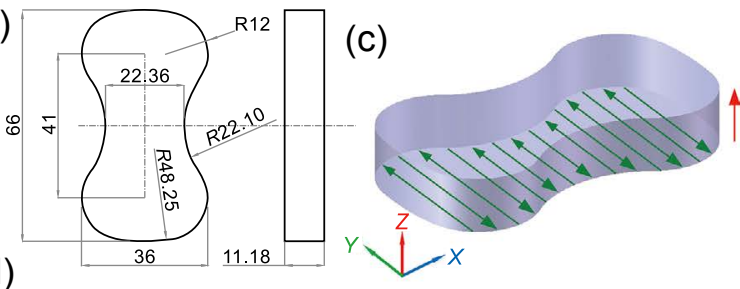

(d)

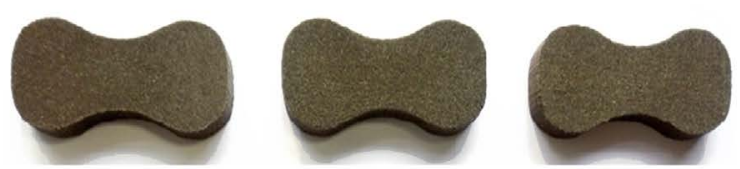

Fig. 3: Preparation of standard tensile samples: (a) self-developed binder jetting sand mold (core) 3D printer; (b) geometry of standard tensile sample ${ }^{[15]}$; (c) printing method of standard tensile sample; (d) printed green tensile samples of coated sand 


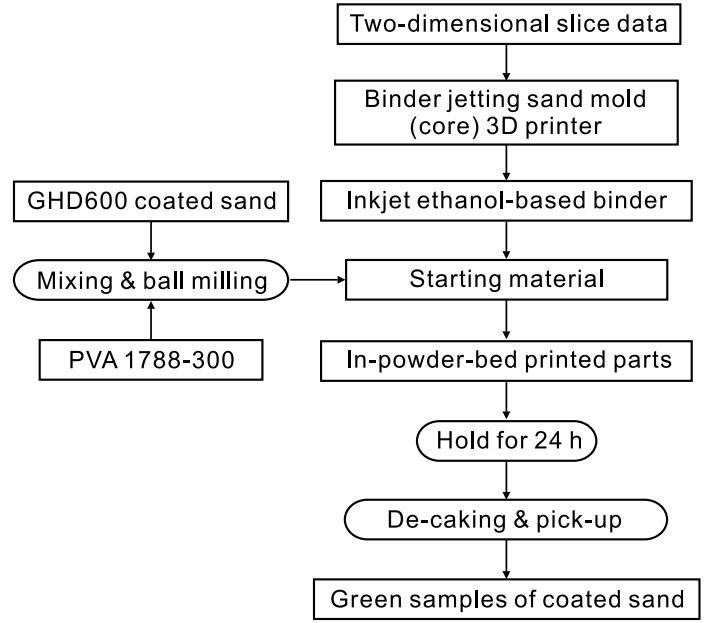

Fig. 4: Process diagram for printing green samples of coated sand

\subsection{Experiments based on Taguchi method}

Experiments based on the Taguchi method ${ }^{[16,17]}$ were carried out to investigate the evolution of the green-part tensile strength as a function of four factors selected from several process analysis and previous studies ${ }^{[18,19]}$. The tensile strength was labelled as the dependent variables for quality control at the design stage, and the factors investigated are the binder alcoholicity, the binder saturation, the layer thickness, and the PVA content. The variational level ranges and values of the influence factors are listed in Table 4. Each influence factor is set 3 levels according to a pre-test. The orthogonal array $\mathrm{L}_{9}\left(3^{4}\right)$ with 3 samples per run was selected to conduct the experiments. After the green samples were obtained, a CMT4304 multifunction statics tester was used to measure their tensile strength. The average tensile strength of each group was then calculated.

Table 4: Influence factors with their values at 3 levels

\begin{tabular}{|c|c|c|c|c|}
\hline \multirow{2}{*}{ Level } & \multicolumn{4}{|c|}{ Influence factors } \\
\hline & $\begin{array}{c}\text { A } \\
\text { (Alcoholicity, wt.\%) }\end{array}$ & $\begin{array}{c}\text { B } \\
\text { (Binder saturation, \%) }\end{array}$ & $\begin{array}{c}\text { C } \\
\text { (Layer thickness, } \mathrm{mm} \text { ) }\end{array}$ & $\begin{array}{c}\text { D } \\
\text { (PVA content, wt.\%) }\end{array}$ \\
\hline Level 1 & 50 & 55 & 0.28 & 1.5 \\
\hline Level 2 & 67 & 65 & 0.32 & 3 \\
\hline Level 3 & 75 & 75 & 0.36 & 4.5 \\
\hline
\end{tabular}

\section{Results and discussion}

\subsection{Physical interpretation of green-part strength}

The formation of the bonding neck ${ }^{[20-22]}$ has an effect on the bonding quality among sand particles and the green-part strength of coated sand. Figure 5(a) shows the mechanism behind the bonding neck formation. The printhead deposits the binder on the powder bed to form a well-defined area which is the single layer of the printed part, and then this area contains binder, coated sand and PVA. The binder serves as the solvent, whereas PVA and the thermoplastic phenolic resin serve as the solute. During the formation of the bonding neck, the linear phenolic resin chains and the PVA chains overcome their intermolecular forces and stretch in the solution. With the volatilization of the binder, the molecular chains entangle with each other [Fig. 5(c)], gradually binding the sand particles together, and the bonding necks firmly form among the sand particles, which contributes to a high green-part strength.

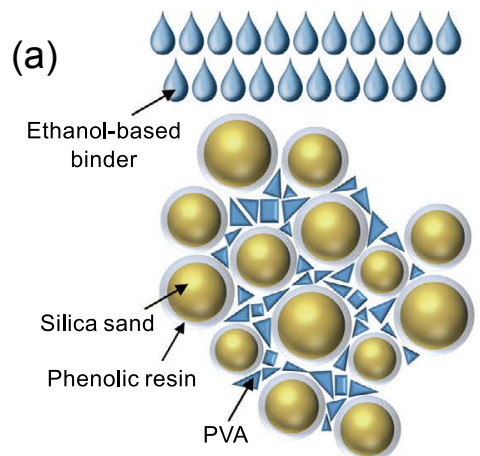

(b)
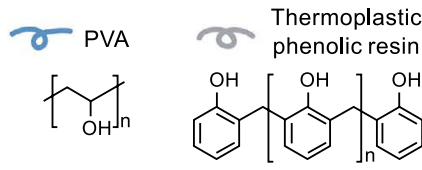
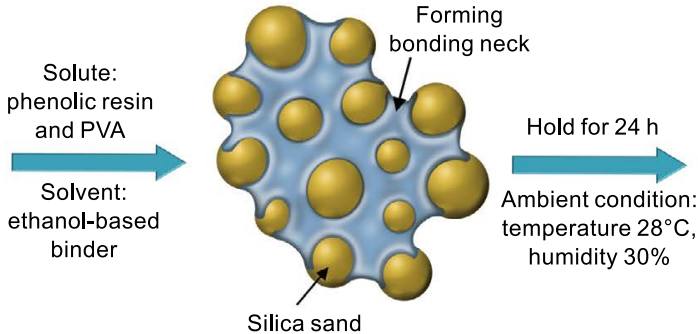

humidity $30 \%$

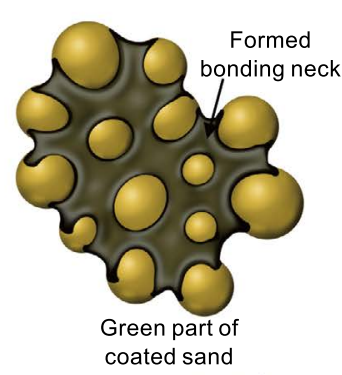

(c)

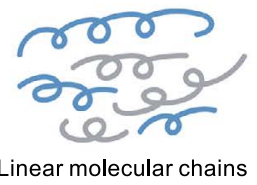

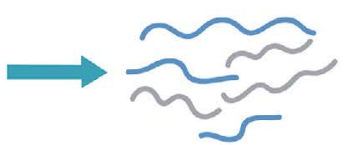

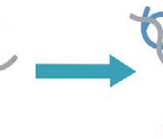

Stretch of molecular chains Entanglement of molecular chains

Fig. 5: Schematic representation of bonding neck formation: (a) formation of bonding necks among sand particles; (b) chemical structures of PVA and thermoplastic phenolic resin; (c) morphology changes of molecular chains during process 


\subsection{Optimal process parameters}

The orthogonal arrays of the Taguchi experiments and the green-part tensile strength of each group are listed in Table 5. The experimental results show that the maximum and minimum values of the green-part tensile strength (average value) are $2.157 \mathrm{MPa}$ in group No. 3 and 0.860 $\mathrm{MPa}$ in group No. 7, respectively. In order to investigate the relation between the influence factors and the green-part tensile strength, range statistics $\left(R_{i}\right)$ was adopted to analyze the experimental data. $R_{i}$ can be defined as follows:

$$
\begin{gathered}
R_{i}=\bar{K}_{i j \max }-\bar{K}_{i j \min }(i=\mathrm{A}, \mathrm{B}, \mathrm{C}, \mathrm{D} ; j=1,2,3) \\
\bar{K}_{i j}=\frac{K_{i j}}{3}(i=\mathrm{A}, \mathrm{B}, \mathrm{C}, \mathrm{D} ; j=1,2,3)
\end{gathered}
$$

where, $K_{i j}(\mathrm{MPa})$ corresponds to the sum of the green-part tensile strength in level $j$ for the factor $i$, whereas $\bar{K}_{i j}(\mathrm{MPa})$ represents the average of the green-part tensile strengths in level $j$ for the factor $i$. The results are summarized in Table 5.

\begin{tabular}{|c|c|c|c|c|c|}
\hline \multirow{2}{*}{ Group } & \multicolumn{4}{|c|}{ Influencing factors } & \multirow{2}{*}{$\begin{array}{l}\text { Average tensile } \\
\text { strength (MPa) }\end{array}$} \\
\hline & $\begin{array}{c}\text { A } \\
\text { (Alcoholicity, wt.\%) }\end{array}$ & $\begin{array}{c}\text { B } \\
\text { (Binder saturation, \%) }\end{array}$ & $\begin{array}{c}\mathrm{C} \\
\text { (Layer thickness, } \mathrm{mm} \text { ) }\end{array}$ & $\begin{array}{c}\text { D } \\
\text { (PVA content, wt.\%) }\end{array}$ & \\
\hline 1 & 50 & 55 & 0.28 & 1.5 & 1.087 \\
\hline 2 & 50 & 65 & 0.32 & 3 & 1.453 \\
\hline 3 & 50 & 75 & 0.36 & 4.5 & 2.157 \\
\hline 4 & 67 & 55 & 0.32 & 4.5 & 1.433 \\
\hline 5 & 67 & 65 & 0.36 & 1.5 & 1.270 \\
\hline 6 & 67 & 75 & 0.28 & 3 & 1.463 \\
\hline 7 & 75 & 55 & 0.36 & 3 & 0.860 \\
\hline 8 & 75 & 65 & 0.28 & 4.5 & 1.350 \\
\hline 9 & 75 & 75 & 0.32 & 1.5 & 1.283 \\
\hline$K_{i 1}$ & 4.697 & 3.380 & 3.900 & 3.640 & \\
\hline$K_{i 2}$ & 4.166 & 4.073 & 4.169 & 3.776 & \\
\hline$K_{i 3}$ & 3.493 & 4.903 & 4.287 & 4.940 & \\
\hline $\bar{K}_{i 1}$ & 1.566 & 1.127 & 1.300 & 1.213 & \\
\hline $\bar{K}_{i 2}$ & 1.389 & 1.358 & 1.390 & 1.259 & \\
\hline $\bar{K}_{i 3}$ & 1.164 & 1.634 & 1.429 & 1.647 & \\
\hline$R_{i}$ & 0.402 & 0.507 & 0.129 & 0.434 & \\
\hline
\end{tabular}

Table 5: Results of Taguchi method-based experiment on binder jetting 3D printing with standard tensile samples of coated sand

Range statistics $\left(R_{i}\right)$ represents the effects of the level variability on the dependent variables: the larger its value, the higher its impact on the result. Table 5 shows the priority of $R_{i}$ is $R_{\mathrm{B}}>R_{\mathrm{D}}>R_{\mathrm{A}}>R_{\mathrm{C}}$. Therefore, the binder saturation (Factor $\mathrm{B}$ ) induces the most significant effects on the green-part tensile strength, which is followed by the PVA content (Factor D), the alcoholicity (Factor A), and the layer thickness (Factor C).

The optimal combination of the process parameters can be defined: A1-B3-C3-D3. The values of the parameters are listed in Table 6. The effect of the process parameters on the green-part tensile strength can be obtained as shown in Fig. 6.

\subsection{Single influencing factor impact}

\subsubsection{Binder saturation}

The binder saturation (S) corresponds to the percentage of pore space $\left(V_{\text {pore }}\right)$, which is occupied by a binder volume
Table 6: Optimal process parameters identified via Taguchi method

\begin{tabular}{cc} 
Process parameters & Value \\
\hline A (Alcoholicity, wt.\%) & 50 \\
B (Binder saturation, \%) & 75 \\
C (Layer thickness, mm) & 0.36 \\
D (PVA content, wt.\%) & 4.5
\end{tabular}

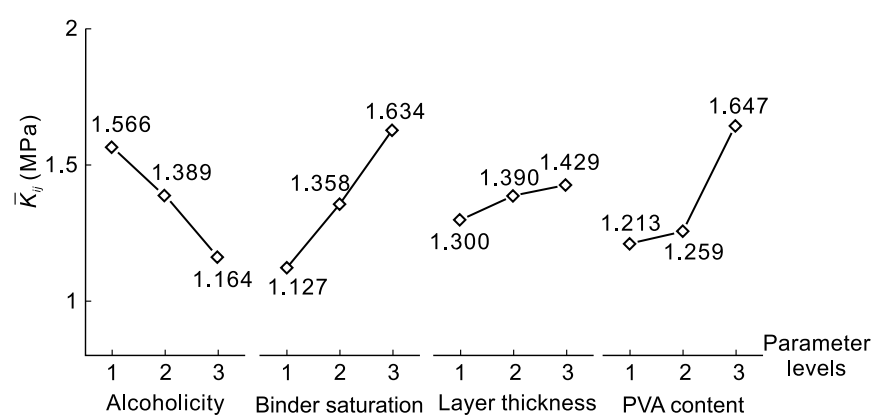

Fig. 6: Effect of process parameters on green-part tensile strength 
$\left(V_{\text {binder }}\right)^{[23]}$, and it can be defined as follows:

$$
\begin{gathered}
S=\frac{V_{\text {binder }}}{V_{\text {pore }}} \times 100 \% \\
V_{\text {pore }}=V_{\text {sample }} \times\left(1-K_{\text {compact }}\right)
\end{gathered}
$$

where, $K_{\text {compact }}$ corresponds to the compactness ratio of the printed sample, which can also be defined as:

$$
K_{\text {compact }}=\frac{\rho_{\mathrm{P}}}{\rho_{\mathrm{R}}} \times 100 \%
$$

where, $\rho_{\mathrm{P}}$ represents the packing density of the mixed powder and $\rho_{\mathrm{R}}$ is the density of the silica sand. According to the results obtained with the BT 1000 powder comprehensive performance tester, $\rho_{\mathrm{R}}$ is $2.65 \mathrm{~g} \cdot \mathrm{cm}^{-3}$ and $\rho_{\mathrm{P}}$ is in the range of $1.79-1.65 \mathrm{~g} \cdot \mathrm{cm}^{-3}$ with a PVA content in the $1.5 \mathrm{wt} . \%-4.5 \mathrm{wt} . \%$. Hence, $K_{\text {compact }}$ is in the range of $62.3 \%-67.5 \%$.

Based on the $R_{i}$ value of each process parameter reported in Table 5, the binder saturation exhibits the most significant impact on the green-part tensile strength. And upon the increase of binder saturation, green-part tensile strength of printed samples gradually increases as shown in Fig. 6 . According to the definition of binder saturation, the larger volume of the binder deposited on the powder bed leads to an increase in the binder saturation, which triggers a higher dissolution of both phenolic resin and PVA together with the formation of bonding necks that firmly connect the particles. This induces an increase in the tensile strength of the printed samples. However, it is not that more saturation is better, since significant swelling of the powder bed and lower printing quality may be observed.

\subsubsection{PVA content and alcoholicity}

The PVA content of the powder and the ethanol content of the binder are mutually related: as the content of ethanol increases, the content of deionized water decreases and the solubility of PVA decreases. Figure 6 shows that, with an increase in the alcoholicity of the binder, the tensile strength of the coated sand sample gradually decreases. In addition, the results in Fig. 6 show that upon an increase in the PVA content, the green-part tensile strength of the coated sand sample gradually increases. SEM images show that in samples without PVA [Figs. 7(a) and (b)], the bonding necks among the sand particles appear tiny and fragile. The resulting bonding necks are very limited due to the only presence of phenolic resin. In samples with $4.5 \mathrm{wt} . \%$ of PVA content [Figs. 7 (c) and (d)], the number of bonding necks among the powder particles increases significantly. It is obvious that the powder particles are all wrapped by the bonding necks, therefore, increasing the tensile strength.
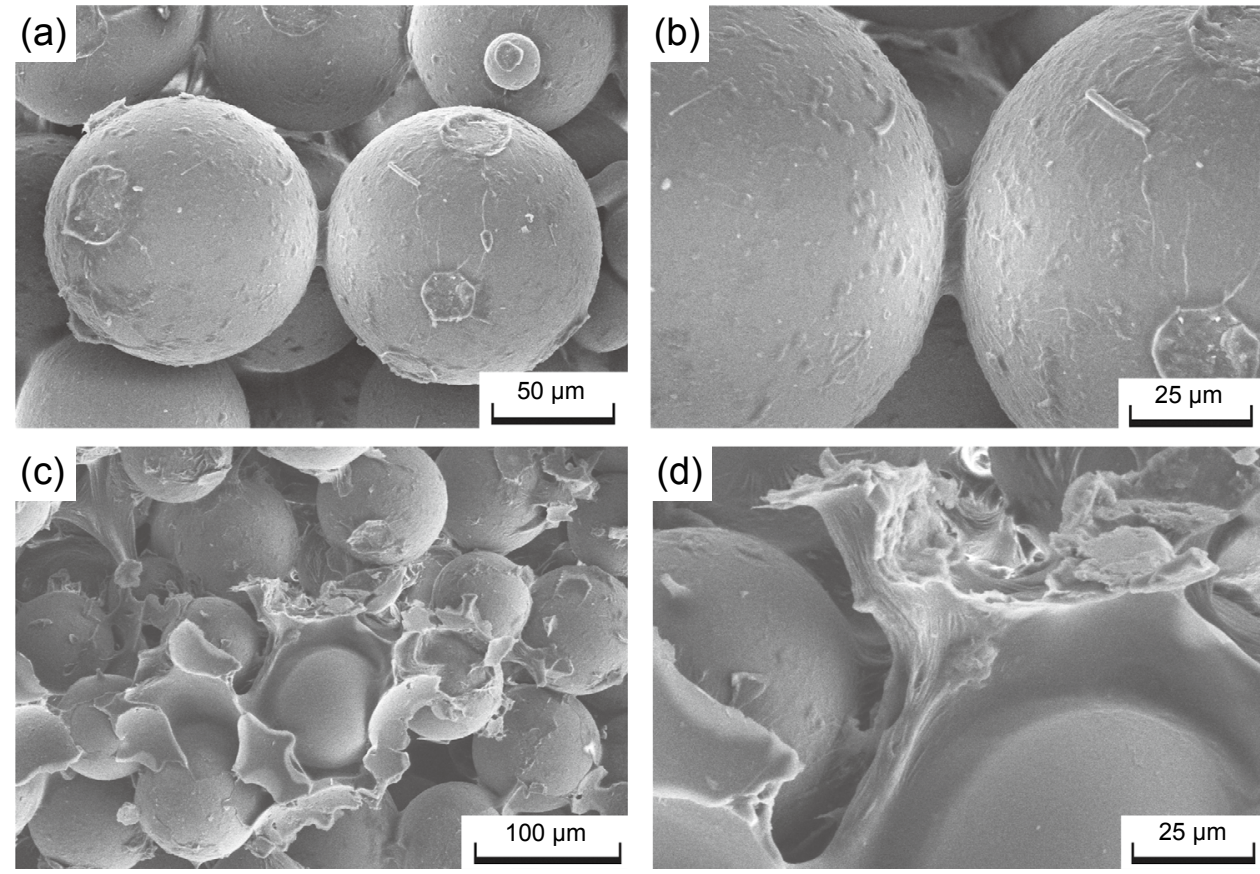

Fig. 7: SEM images of bonding necks: (a) and (b) bonding necks without PVA; (c) and (d) bonding necks with 4.5wt.\% PVA content

To verify the content of PVA in the samples with optimal process parameters, a set of starting materials with different PVA contents (3wt.\%, 4.5wt.\%, 6wt.\%, 7.5wt.\%) was prepared according to the powder preparation method of Section 2.1. The remaining parameters are $50 \mathrm{wt} . \%$ of alcoholicity, $75 \%$ of binder saturation and $0.36 \mathrm{~mm}$ of layer thickness. These compounds were used to print a set of standard tensile samples, and their tensile strength was measured. The fracture morphology of tensile samples after the test is shown in Fig. 8. When the PVA content is 3 wt.\% [Fig. 8(a)] and 4.5wt.\% [Fig. 8(b)], the samples show a relatively uniform crack (tensile strength: $1.46 \mathrm{MPa}$ and $1.73 \mathrm{MPa}$, respectively). When the content of PVA increases to $6 \mathrm{wt} . \%$ [Fig. 8(c)], irregular cracks appear along the fracture surface (tensile strength: 0.89 MPa). When 
the PVA content further increases to $7.5 \mathrm{wt} . \%$ [Fig. 8(d)], the sample not only breaks from the middle, but also peels off between the layers during the tensile test. The fracture surface appears extremely uneven, and the tensile sample seriously delaminates with poor interlayer bonding. Its tensile strength measures, in this case, only $0.38 \mathrm{MPa}$. (a)

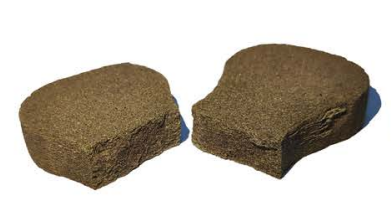

(b)

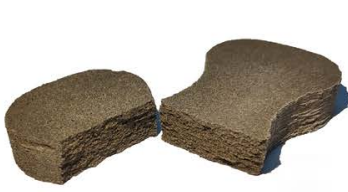

(c)

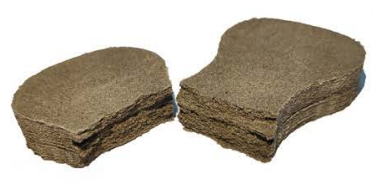

(d)

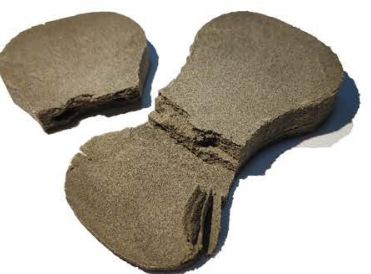

Fig. 8: Fracture morphology of tensile samples with different PVA content: (a) 3wt.\%; (b) 4.5wt.\%; (c) 6wt.\%; (d) 7.5wt.\%

\subsubsection{Layer thickness}

The layer thickness mostly affects the printing resolution and the smallest possible printable feature size. However, the results collected so far show that the layer thickness has a limited influence on the green-part tensile strength. Under the condition of a certain forming height, the thicker the layer, the fewer the slices obtained. This may reduce the stress on the surface and the number of cracks, increasing the greenpart tensile strength. Figure 6 shows that upon an increase in the layer thickness, the green-part tensile strength gradually increases. The optimal value of the layer thickness is $0.36 \mathrm{~mm}$ in this work.

\subsection{Sand pattern printing}

An engine cylinder head sand pattern with complex cavity structures was printed with the optimal parameters obtained in Section 3.2, i.e., the binder was prepared with a solution containing 50wt.\% alcohol, $3 \mathrm{wt} . \%$ surfactant, and $47 \mathrm{wt} . \%$ deionized water; the molding powder consisted of coated sand and $4.5 \mathrm{wt} . \%$ PVA; the 3D printer was set to obtain a layer thickness of $0.36 \mathrm{~mm}$ and a printing saturation of $75 \%$. The printed engine cylinder head pattern is shown in Fig. 9(a). Four standard tensile samples of coated sand were arranged symmetrically in the forming box. After printing, the parts remained in the forming box for $24 \mathrm{~h}$ at a temperature of $28{ }^{\circ} \mathrm{C}$ and $30 \%$ humidity. Then, a vacuum cleaner was used to remove the loosely attached powder, and the green-part samples were obtained. Figure 9(b) shows the stress-strain curve: the maximum value of tensile strength measures $2.31 \mathrm{MPa}$.

No signs of collapsing structures are visible in the engine cylinder head pattern, and the complex cavities remain intact after de-caking and the pick-up procedure. The high green strength of the sample guarantees its integrity and reduces failures in the thin-walled and small-sized structures of the green parts. (a)

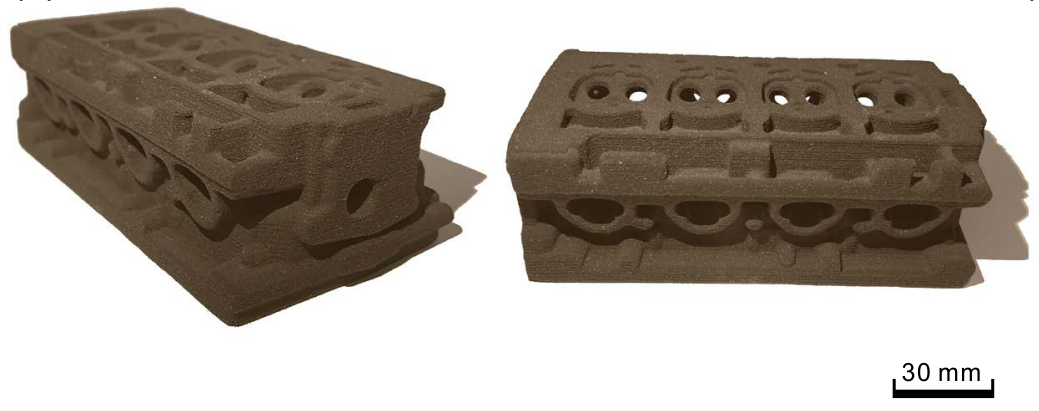

(b)

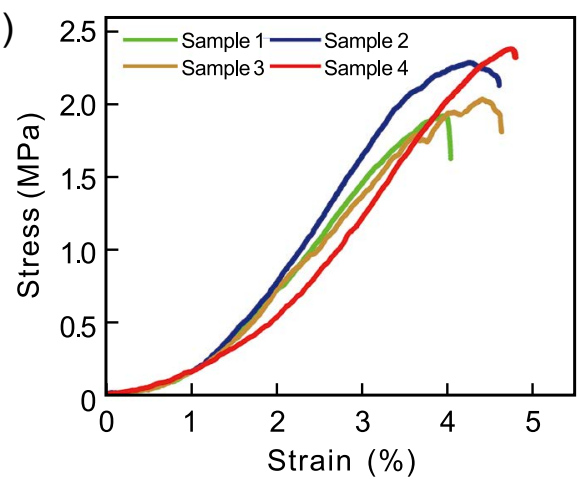

Fig. 9: Green part of an engine cylinder head sand pattern printed (a), and stress-strain curve of standard tensile samples printed (b) with optimal process parameters

\subsection{Trial-produce of casting}

To further verify the casting performance of the printed sand mold, an impeller shape was chosen as the prototype to design the casting molds [Fig. 10(a)]. The upper and bottom molds were printed separately, adopting the optimal process parameters, and then they were baked in an oven at $220^{\circ} \mathrm{C}$ for $2 \mathrm{~h}$. This procedure aims to form the final strength of the coated sand molds, and to decompose the PVA in the powder material to reduce the gas evolution. The sand molds after baking are shown in Fig. 10(b). Before casting, the surface of the mold cavity was coated with zircon powder water-based coating and the final molds used for the impeller shape casting are shown in Fig. 10(c). The ZL301 aluminum alloy impeller shape casting was prepared at the pouring temperature of $700{ }^{\circ} \mathrm{C}$, as shown in Fig. 10(d). The gas evolution volume of the printed sand mold obtained by the FQX-2000A gas tester at $1,000{ }^{\circ} \mathrm{C}^{[15]}$ measured $22.13 \mathrm{~mL} \cdot \mathrm{g}^{-1}$. 


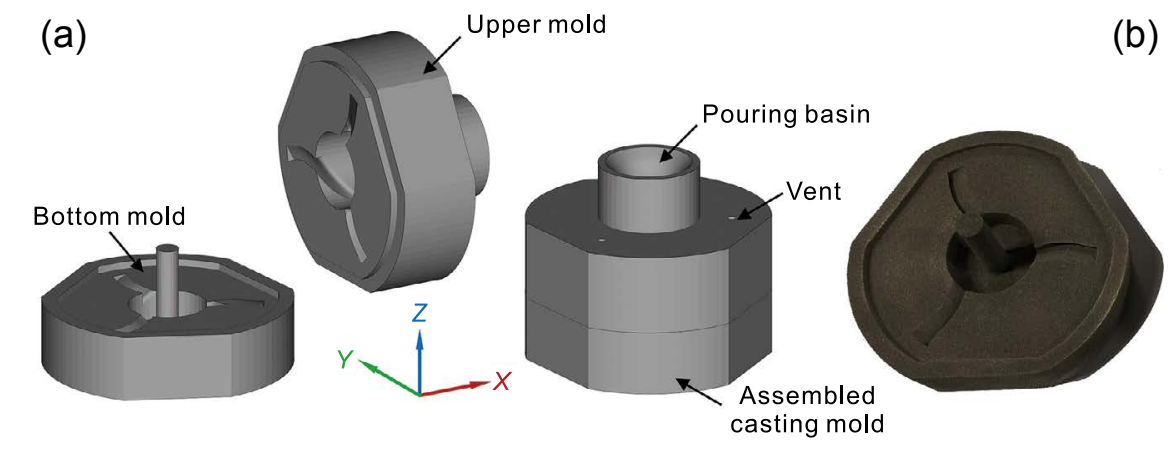

(b)

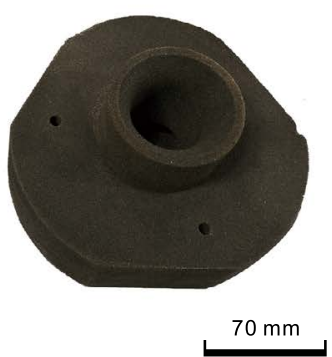

(c)

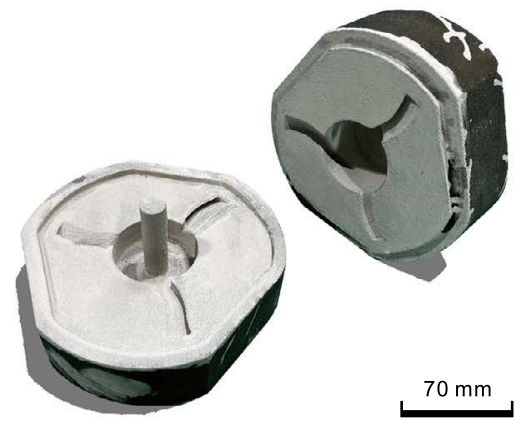

(d)
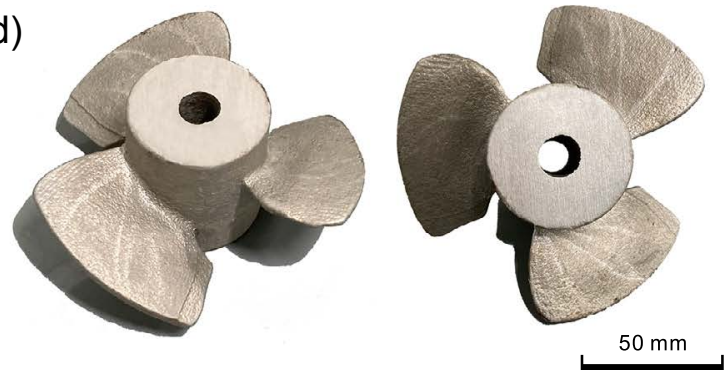

Fig. 10: Trial-production of casting: (a) 3D model of sand molds; (b) sand molds after drying at $220^{\circ} \mathrm{C}$ for $2 \mathrm{~h}$; (c) molds with zircon powder water-based coating; (d) cast impeller

A column test sample $(35 \mathrm{~mm}$ in diameter, $6 \mathrm{~mm}$ in thickness) was cut from the impeller shape casting. The versatile X-ray microfocus CT system (Phoenix v|tome|x m) was used to obtain the $3 \mathrm{D}$ quantitative porosity analysis of the test sample (Fig. 11). The detection results are listed in Table 7.

The result of the trial-production yields an intact casting shape and a legible contour, and there are no obvious pores on the surface of the impeller shape casting. The surface quality with a roughness of $25 \mu \mathrm{m}$ was measured by the TR300 contour graph device, and the CT detection results show the porosity for the interior of the casting (Table 7 ) is $0.74 \%$. The maximum diameter of pore is $1.586 \mathrm{~mm}$, the minimum diameter of pore is only $0.048 \mathrm{~mm}$, and the proportion of pores above $0.5 \mathrm{~mm}$ diameter accounts for only $0.08 \%$, which indicates a relatively high quality of the casting.

\section{Conclusions}

A binder jetting 3D printing process able to produce green parts with a high tensile strength was proposed. Experiments
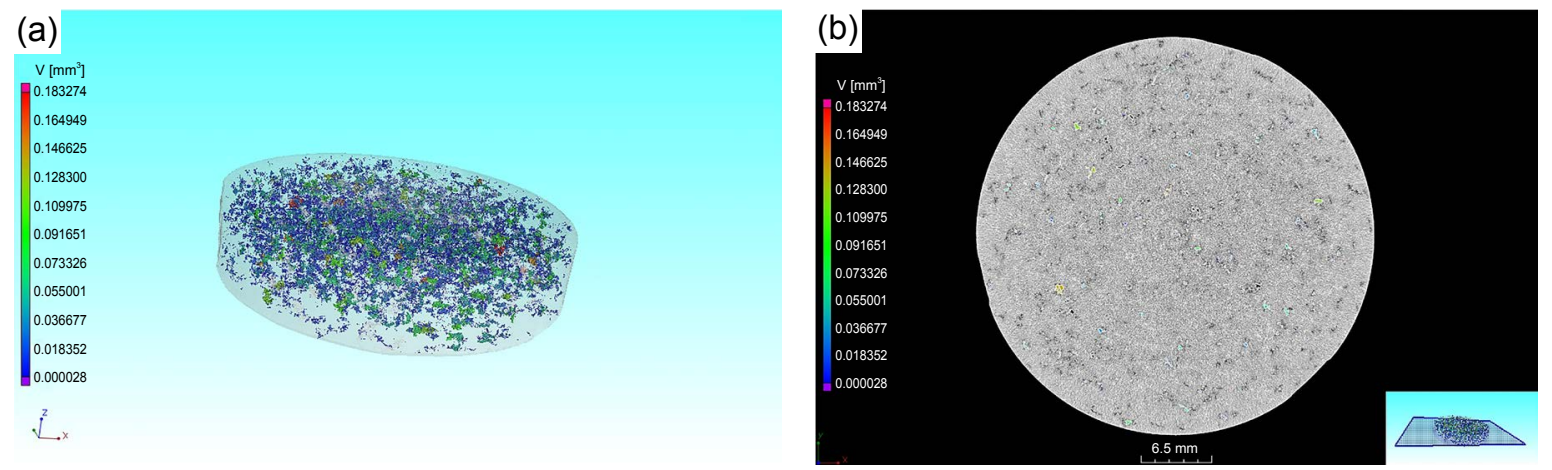

Fig. 11: 3D quantitative porosity analysis of column test sample: (a) three-dimensional image; (b) section image

Table 7: Detection results of versatile X-ray microfocus CT system

\begin{tabular}{cccc} 
Porosity $(\%)$ & $\begin{array}{c}\text { Minimum pore } \\
\text { diameter }(\mathrm{mm})\end{array}$ & $\begin{array}{c}\text { Maximum pore } \\
\text { diameter }(\mathrm{mm})\end{array}$ & $\begin{array}{c}\text { Proportion of pores above } \\
\mathbf{0 . 5} \mathrm{mm} \text { diameter }(\%)\end{array}$ \\
\hline 0.74 & 0.048 & 1.586 & 0.08
\end{tabular}


based on the Taguchi method were carried out to investigate the relation between the process parameters and the greenpart tensile strength. Based on the optimal process parameters identified via Taguchi method-based experiment, the relevant verifications were carried out. Accordingly, the following conclusions can be drawn:

(1) The optimal process parameters are a binder alcoholicity of $50 \mathrm{wt} . \%$, a binder saturation of $75 \%$, a layer thickness of $0.36 \mathrm{~mm}$, and a PVA content of $4.5 \mathrm{wt} . \%$. The binder saturation has the most significant influence on the green-part tensile strength, followed by the PVA content, the alcoholicity, and the layer thickness.

(2) A sand pattern with complex cavity structures printed with optimal process parameters confirms that the proposed binder jetting $3 \mathrm{D}$ printing process enables the manufacturing of green sand parts with a high shape-retention ability. Moreover, the green tensile strength of a coated sand sample reaches $2.31 \mathrm{MPa}$.

(3) The sand mold of a ZL301 aluminum alloy impeller shape casting was prepared by $3 \mathrm{D}$ printing adopting the optimal process parameters. The gas evolution volume of the mold is $22.13 \mathrm{~mL} \cdot \mathrm{g}^{-1}$. The trial-production yields an intact casting shape and a legible contour. There are no obvious pores on the surface of the impeller, and the internal also has a relatively low porosity, measures $0.74 \%$.

\section{Acknowledgement}

This work was financially supported by the National Key Research and Development Program of China (No. 2018YFB1106800).

\section{References}

[1] Sama S R, Wang J, Manogharan G. Non-conventional mold design for metal casting using 3D sand-printing. Journal of Manufacturing Processes, 2018, 34: 765-775.

[2] Lores A, Azurmendi N, Agote I, et al. A review on recent developments in binder jetting metal additive manufacturing: Materials and process characteristics. Powder Metallurgy, 2019, 62(5): 267-296.

[3] Sachs E M, Haggerty J S, Cima M J, et al. Three-dimensional printing techniques. United States, US5204055A, 20th April, Massachusetts Institute of Technology, 1993.

[4] ISO/ASTM52900-15, Standard terminology for additive manufacturing-General principles-Terminology.

[5] Zhao S M, Yao S, Yang T. Influence of resin flow on shrinkage of additive manufacturing coated sand molds. China Foundry, 2018, 15(4): 291-298.

[6] Upadhyay M, Sivarupan T, El Mansori M. 3D printing for rapid sand casting - A review. Journal of Manufacturing Processes, 2017, 29: 211-220.
[7] Snelling D, Blount $H$, Forman $C A$, et al. The effects of $3 D$ printed molds on metal castings. In: Proc. 24th International SFF Symposium - An Additive Manufacturing Conference, SFF, 2013: 827-845.

[8] Drokina V V, Belov V D, Chekhonin S N. Obtaining casts of aluminum alloys by foundry in loose molds fabricated on installations of three-dimensional printing. Russian Journal of Non-Ferrous Metals, 2011, 52(1): 24-28.

[9] Snelling D, Williams C, Druschitz A. A comparison of binder burnout and mechanical characteristics of printed and chemically bonded sand molds. SFF Symp, 2014: 197-209.

[10] Tian L, Wei Q S, Mao Y W, et al. Effect of $\alpha$-Plaster content on properties of coated sand fabricated by three-dimensional printing. Special Casting \& Nonferrous Alloys, 2016, 36(12): 1305-1308. (In Chinese)

[11] Zhao H P, Ye C S, Fan Z T, et al. Effect of binder system on accuracy and property of micro-Jetting and bonding formed sand molds. Foundry, 2017, 66(3): 223-227. (In Chinese)

[12] Jia Z H, Fu S X. Metal material liquid forming process. Beijing: Chemical Industry Press, 2008: 30-41. (In Chinese)

[13] Choi H-H, Kim E-H, Park H-Y, et al. Application of dual coating process and $3 \mathrm{D}$ printing technology in sand mold fabrication. Surface and Coatings Technology, 2017, 332: 522-526.

[14] Xiong Y Y, Qian C, Sun J. Fabrication of porous titanium implants by three-dimensional printing and sintering at different temperatures. Dental Materials Journal, 2012, 31(5): 815-20.

[15] GB/T 2684-2009, Test methods for foundry sands and molding mixtures. (In Chinese)

[16] D'souza A D, Rao S S, Herbert M A. Taguchi method of optimization of process variables for ultimate tensile strength of friction stir welded joint of Al-Ce-Si-Mg aluminium alloy plates. Materials Today: Proceedings, 2021.

[17] Shi Y. Mathematical Statistics. Xi'an: Xi'an Jiaotong University Press, 2018: 156-167. (In Chinese)

[18] Li S J, Cao S. Print parameters influence on parts' quality and calibration with 3DP-Part I: Print parameters influence on parts' surface topography. Advanced Materials Research, 2012, 399-401: 1639-1645.

[19] Li S J, Cao S. Print parameters influence on parts' quality and calibration with 3DP-Part II: Print parameters calibration and contour Accuracy control. Advanced Materials Research, 2012, 399-401: 1687-1692.

[20] Fan C Z, Shan Z D, Zou G S, et al. Interfacial bonding mechanism and mechanical performance of continuous fiber reinforced composites in additive manufacturing. Chinese Journal of Mechanical Engineering, 2021, 34(1): 21-32.

[21] Nandwana P, Elliott A M, Siddel D, et al. Powder bed binder jet 3D printing of Inconel 718: Densification, microstructural evolution and challenges. Current Opinion in Solid State and Materials Science, 2017, 21(4): 207-218.

[22] Bai Y, Williams C B. The effect of inkjetted nanoparticles on metal part properties in binder jetting additive manufacturing. Nanotechnology, 2018, 29(39): 395706.

[23] Chen H, Zhao Y F. Process parameters optimization for improving surface quality and manufacturing accuracy of binder jetting additive manufacturing process. Rapid Prototyping Journal, 2016, 22(3): 527-538. 